\title{
SIKAP SISWA DAN PEMAHAMAN KONSEP MATEMATIS DALAM PEMBELAJARAN GEOMETRI
}

\author{
Risma Nurul Auliya \\ Program Studi Informatika, Universitas Indraprasta PGRI \\ Email: rismauliya@gmail.com
}

\begin{abstract}
Abstrak
Tujuan dari penelitian ini adalah untuk mengetahui bagaimana sikap siswa dalam belajar geometri dan bagaimana pengaruh sikap geometri tersebut terhadap kemampuan pemahaman konsep siswa. Penelitian ini merupakan penelitian survei dengan pendekatan kuantitatif. Penelitian dilakukan di salah satu SMP Negeri di Rangkasbitung pada tahun 2018. Sampel penelitian terdiri dari 61 orang siswa kelas 9. Instrumen penelitian berupa survei digunakan untuk mengetahui sikap siswa terhadap geometri, sedangkan soal uraian digunakan untuk mengukur kemampuan pemahaman konsep matematis. Data penelitian dianalisis dengan menggunakan analisis regresi linear. Hasil penelitian menunjukkan sikap geometri berpengaruh positif dan signifikan terhadap kemampuan pemahaman konsep matematis siswa, serta menghasilkan model matematis dari regresi linear, yaitu $\mathrm{Y}=3,214+$ $0,725 \mathrm{x}$, di mana variabel $\mathrm{x}$ menunjukkan sikap terhadap geometri dan variabel y menunjukkan kemampuan pemahaman konsep matematis. Lebih jauh, dari kuesioner mengenai sikap siswa terhadap geometri diketahui bahwa sebagian besar siswa merasa menikmati belajar geometri dan beranggapan bahwa pelajaran geometri dapat diterapkan dalam kehidupan sehari-hari.
\end{abstract}

Kata kunci: sikap siswa, pemahaman konsep matematis, geometri.

\begin{abstract}
The aim of this study was intended to examine the effect of conceptual understanding towards students' attitude in geometry, and to study how students' attitude in learning geometry, and to study how students behave in learning geometry. The research utilized a survey method with quantitative approach. This research was conducted at one of junior high school in Rangkasbitung in 2018. The sample consisted of 61 secondary school students in grade 9. A survey instrument was intended to examine students' attitude in geometry, and essay problems was to measured conceptual understanding ability in mathematics. The data collected was analyzed using linear regression analysis. The result revealed that students' attitude in geometry was found to be significantly and positively related to conceptual understanding ability. The linear regression analysis estimated the linear regression function to be $Y=3,214+0,725 x$, where $x$ represented attitude in geometry and $Y$ represented conceptual understanding ability. Furthermore, from the attitude survey it was known that most students enjoy geometry and have a positive attitude that geometry can be used in daily life.
\end{abstract}

Keywords: students' attitude in geometry, conceptual understanding ability in mathematics.

\section{PENDAHULUAN}

Cherney, Isil dan Ubuz menyatakan bahwa geometri merupakan salah satu cabang ilmu matematika yang paling penting karena berkaitan dengan pengetahuan mengenai sifat serta hubungan dari garis, sudut, dan bentuk suatu benda yang seringkali ditemukan dalam kehidupan sehari-hari [1]. Cantürk-Günhan and Baser menyatakan bahwa geometri membantu manusia untuk mendefinisikan dunia secara sistematis [2]. Bindak menambahkan bahwa geometri juga berperan dalam mengembangkan beberapa kemampuan, seperti menciptakan penemuan baru, menganalisis suatu masalah, serta menghubungkan matematika dengan situasi pada kehidupan nyata [1]. Selain itu, Suydam menjelaskan bahwa dengan mempelajari geometri, siswa juga dapat memiliki kemampuan intuisi spasial mengenai dunia nyata, serta memiliki keterampilan untuk memahami dan menginterpretasikan suatu argumen matematis [3]. 
NCTM menegaskan bahwa geometri merupakan suatu wadah yang alami untuk mengembangkan kemampuan penalaran siswa dalam pembelajaran matematika [1]. Belajar geometri dapat menjadi suatu kegiatan yang amat menyenangkan atau menjadi suatu tantangan bagi seseorang yang memiliki kemampuan pemahaman konsep geometri yang baik [4]. Greeno, Riley, dan Gelman berpendapat bahwa siswa yang memiliki kemampuan pemahaman konsep yang baik akan mampu untuk menerapkan konsep dan cara yang tepat dalam menyelesaikan suatu masalah matematika [5]. Pemahaman konsep matematis merupakan suatu pengetahuan yang melibatkan pemahaman mengenai konsep yang mendasari suatu algoritma atau perhitungan dalam matematika [6].

Bayram; Etukudo; Odeleye, Oluwatimilehin dan Okereke berkeyakinan bahwa salah satu cara untuk meningkatkan pemahaman konsep yang lebih baik sehingga pembelajaran di kelas lebih bermakna, yaitu adanya sikap positif siswa terhadap suatu pelajaran [7]. Sikap dapat dianggap sebagai kecenderungan belajar yang berakibat pada tindakan seseorang, baik tindakan yang menguntungkan (positif) ataupun tidak menguntungkan (negatif) [8]. Sikap terhadap geometri merupakan sikap yang muncul dalam lingkungan pembelajaran geometri di kelas. Bindak beranggapan bahwa jika siswa memiliki sikap positif terhadap geometri mereka diharapkan menyukai geometri, berpartisipasi dalam pembelajaran di kelas dan memiliki prestasi yang baik dalam pembelajaran geometri [2]. Karena anak-anak akan belajar lebih efektif ketika mereka tertarik pada apa yang mereka pelajari (Ma dan Kishor, dalam [2]).

Beberapa hasil penelitian yang telah dilakukan oleh [3] dan [6] hanya menunjukkan bahwa sikap siswa terhadap geometri berpengaruh langsung terhadap prestasi belajar siswa secara umum. Oleh karena itu, penelitian ini dilakukan dengan tujuan untuk mengetahui bagaimana sikap siswa dalam belajar geometri dan bagaimana pengaruh sikap geometri tersebut terhadap kemampuan pemahaman konsep siswa.

\section{METODE}

Penelitian ini merupakan penelitian survei dengan pendekatan kuantitatif. Penelitian dilakukan di salah satu SMP Negeri di Rangkasbitung pada tahun 2018, dengan jumlah sampel penelitian adalah 61 orang siswa kelas 9, yang dipilih dengan teknik purposive sampling.

Data diperoleh dari hasil tes pemahaman konsep matematis dan kuesioner mengenai sikap siswa pada pembelajaran geometri di kelas. Tes pemahaman konsep matematis terdiri dari lima soal uraian mengenai bangun ruang sisi datar, dengan nilai maksimal adalah 25. Kuesioner mengenai sikap siswa terhadap pembelajaran geometri diadaptasi dari kuesioner yang dikembangkan oleh Bulut, Ekici, Işeri and Helvaci [9], yang terdiri dari 20 item pernyataan. Kuesioner terdiri dari empat pilihan jawaban berdasarkan skala Likert, yaitu sangat setuju (ss), setuju (s), tidak setuju (ts), dan sangat tidak setuju (sts). Setelah dilakukan uji validitas dan reliabilitas, kuesioner yang digunakan sebagai instrumen dalam penelitian ini terdiri dari 16 pernyataan, yang meliputi aspek enjoyment (kesenangan), kecemasan, dan kegunaan geometri. Semakin tinggi skor sikap geometri yang diperoleh, maka menunjukkan bahwa siswa tersebut memiliki sikap geometri yang lebih baik (positif).

\section{HASIL DAN PEMBAHASAN}

Sikap siswa terhadap pembelajaran geometri 
Tabel 1 menunjukkan bahwa sebagian besar siswa merasa bahwa pelajaran geometri menyenangkan dan tidak membosankan. Siswa rela untuk menyediakan waktunya untuk mempelajari geometri dan mempelajarinya lebih jauh lagi. Hal ini dikarenakan sebagian besar siswa beranggapan bahwa belajar geometri dapat membantu mereka dalam mengembangkan kemampuan berpikir. Selain itu, sebagian besar siswa juga beranggapan bahwa pelajaran geometri dapat diterapkan dalam kehidupan seharihari. Siswa memiliki kesempatan untuk menggunakan pengetahuan mengenai geometri yang telah dipelajarinya dalam kehidupan sehari-hari [9]. Dalam hal ini, Tournasis juga menambahkan bahwa pengetahuan geometri sangat penting bukan hanya agar hidup bermasyarakat lebih efektif, tetapi juga berkontribusi terhadap perkembangan suatu lingkungan [2]. Dari tabel 1 juga terlihat bahwa masih banyak siswa yang mengalami kesulitan dalam mempelajari geometri. Namun begitu, menurut Tapia dan Marsh tidak banyak siswa merasa cemas ketika mempelajari geometri, hal ini dikarenakan siswa merasa senang dalam mempelajarinya [9]. Kesadaran siswa akan manfaat geometri dalam kehidupan seharihari juga memberikan dampak bagi turunnya tingkat kecemasan dalam belajar geometri [9]. Baykul menambahkan bahwa konsep geometri berperan untuk mempelajari konsep ilmu matematika lainnya [3]. Siswa juga tak sungkan untuk memahami geometri lebih jauh lagi.

Menurut Ma dan Kishor; Bindak; Kempa dan Dude bahwa ketertarikan siswa terhadap pelajaran geometri menyebabkan munculnya partisipasi aktif siswa, sehingga pembelajaran geometri dinilai berjalan lebih efektif [1]. Siswa yang mempelajari geometri dengan sungguhsungguh akan mampu menyelesaikan persoalan geometri dengan baik pula sehingga yakin mendapatkan hasil yang baik juga. Mereka percaya bahwa bukan hanya orang yang pandai saja, tetapi semua orang dapat memahami geometri.

Tabel 1. Hasil Kuesioner Sikap Siswa terhadap Pembelajaran Geometri

\begin{tabular}{|c|c|c|c|c|c|}
\hline $\begin{array}{l}\text { No. } \\
\text { item }\end{array}$ & Pernyataan & $\begin{array}{l}\text { SS } \\
(\%)\end{array}$ & $\begin{array}{c}\mathrm{S} \\
(\%)\end{array}$ & $\begin{array}{l}\text { TS } \\
(\%)\end{array}$ & $\begin{array}{l}\text { STS } \\
(\%)\end{array}$ \\
\hline & A. Kesenangan (enjoyment) & & & & \\
\hline 1. & Saya merasa bosan ketika mempelajari geometri & 3 & 15 & 75 & 7 \\
\hline 2. & Saya tertarik untuk mempelajari geometri & 21 & 66 & 10 & 3 \\
\hline 3. & $\begin{array}{l}\text { Bagi saya, geometri merupakan topik yang sangat } \\
\text { menyenangkan }\end{array}$ & 16 & 74 & 5 & 5 \\
\hline 4. & Saya menyukai pelajaran geometri & 16 & 70 & 10 & 3 \\
\hline 5. & Saya tidak memiliki keinginan untuk mempelajari geometri & 3 & 11 & 67 & 18 \\
\hline 11. & Saya belajar geometri dengan senang hati & 23 & 69 & 5 & 3 \\
\hline 12. & $\begin{array}{l}\text { Saya rela menghabiskan sebagian besar waktu belajar saya } \\
\text { untuk mempelajari geometri }\end{array}$ & 10 & 62 & 25 & 3 \\
\hline 13. & $\begin{array}{l}\text { Saya senang mempelajari geometri lebih jauh lagi } \\
\text { B. Efficacy }\end{array}$ & 21 & 67 & 8 & 4 \\
\hline 14. & $\begin{array}{l}\text { Saya yakin mendapatkan hasil yang baik dalam pelajaran } \\
\text { geometri }\end{array}$ & 23 & 64 & 10 & 3 \\
\hline 15. & Hanya orang pandai yang dapat memahami geometri & 3 & 11 & 48 & 38 \\
\hline 16. & $\begin{array}{l}\text { Kemampuan saya dalam geometri merupakan yang terendah } \\
\text { dibandingkan dengan materi lainnya } \\
\text { C. Kecemasan (anxiety) }\end{array}$ & 10 & 18 & 51 & 21 \\
\hline 9. & Saya cemas ketika mempelajari geometri & 5 & 21 & 66 & 8 \\
\hline 10. & $\begin{array}{l}\text { Saya merasa kesulitan dalam mempelajari geometri } \\
\text { D. Kegunaan }\end{array}$ & 5 & 46 & 44 & 5 \\
\hline 6. & Belajar geometri tidak dapat membantu dalam & 3 & 13 & 64 & 20 \\
\hline
\end{tabular}


mengembangkan kemampuan berpikir

7. Akan lebih baik jika geometri tidak diajarkan di sekolah

8. Saya dapat menerapkan pelajaran geometri dalam kehidupan sehari-hari

Pengaruh sikap geometri terhadap kemampuan pemahaman konsep matematis

Uji statistik regresi linear dilakukan untuk mengetahui pengaruh sikap geometri terhadap kemampuan pemahaman konsep matematis. Dalam pengujian menggunakan regresi linear perlu dilakukan uji asumsi linear klasik, meliputi uji normalitas, linearitas, autokorelasi, dan heterokedastisitas. Berdasarkan hasil perhitungan menggunakan SPSS diperoleh bahwa data yang digunakan memenuhi seluruh asumsi linear klasik tersebut.
Kemudian, dilakukan uji kelayakan model regresi untuk mengetahui besarnya persentase sikap geometri dalam menjelaskan kemampuan pemahaman konsep matematis yang ditunjukkan oleh koefisien determinasi $\left(\mathrm{R}^{2}\right)$ yang diperoleh (tabel 2). Tabel 2 menunjukkan bahwa besarnya koefisien determinasi, yaitu 0,769 atau $76,9 \%$, berarti besarnya pengaruh sikap geometri terhadap kemampuan pemahaman matematis adalah sebesar $76,9 \%$, sedangkan $23,1 \%$ dipengaruhi oleh faktor lainnya.

Tabel 2. Koefisien Determinasi $\left(\mathbf{R}^{2}\right)$

\begin{tabular}{ccccc}
\hline Model & $\mathrm{R}$ & $\mathrm{R}$ Square & Adjusted R Square & Std. Error of the Estimate \\
\hline 1 & $0,877^{\mathrm{a}}$ & 0,769 & 0,765 & 1,474 \\
\hline & a. Predictors: (Constant), sikap &
\end{tabular}

Selanjutnya, pengujian menggunakan analisis regresi liner menghasilkan model matematis dari regresi linear (lihat tabel 3), yaitu sebagai berikut:

$$
\mathrm{Y}=3,214+0,725 \mathrm{x}
$$

Nilai 3,214 merupakan nilai konstanta yang menunjukkan bahwa jika ada sikap geometri maka pemahaman konsep matematis akan mencapai 35,242. Koefisien regresi $\mathrm{x}$ sebesar 0,725 menyatakan bahwa setiap ada penambahan satu nilai untuk sikap geometri akan meningkatkan kemampuan pemahaman konsep matematis sebesar 0,725 .

Tabel 3. Persamaan Regresi Linear

\begin{tabular}{|c|c|c|c|c|c|c|}
\hline & \multirow[b]{2}{*}{ Model } & Unstanda & Coefficients & \multirow{2}{*}{$\begin{array}{c}\text { Standardized } \\
\text { Coefficients }\end{array}$} & \multirow[b]{2}{*}{$\mathrm{t}$} & \multirow[b]{2}{*}{ Sig. } \\
\hline & & B & Std. Error & & & \\
\hline \multirow[t]{2}{*}{1} & (Constant) & 3,214 & 1,061 & & 3,029 & 0,004 \\
\hline & Attitude & 0,725 & 0,052 & 0,877 & 14,002 & 0,000 \\
\hline
\end{tabular}

a. Dependent Variable: understanding

Keberartian persamaan regresi yang diperoleh dapat diuji dengan menggunakan uji F. Adapun, hipotesis yang diuji, yaitu:

$\mathrm{H}_{0}$ : Sikap geometri tidak berpengaruh signifikan terhadap kemampuan pemahaman konsep matematis.

$\mathrm{H}_{1}$ : Sikap geometri tidak berpengaruh signifikan terhadap kemampuan pemahaman konsep matematis.
Hasil perhitungan uji $\mathrm{t}$ dan uji $\mathrm{F}$ pada taraf signifikansi $\alpha=0,05$, dapat dilihat pada Tabel 4, yang menunjukkan bahwa nilai signifikansi, yaitu $0,000<\alpha$, yang berarti $\mathrm{H}_{0}$ ditolak. Jadi, dapat disimpulkan bahwa sikap geometri berpengaruh signifikan terhadap kemampuan pemahaman konsep matematis siswa. Sikap positif dan negatif 
memberikan pengaruh yang berbeda terhadap pembelajaran, serta naik atau turunnya prestasi seseorang bergantung pada sikap belajar ketika di kelas [6]. Ketika siswa merasa bahwa memahami konsep suatu pelajaran merupakan hal yang sulit, maka perlahan-lahan akan muncul rasa tidak suka pada pelajaran tersebut [7]. Selaras dengan hasil penelitian yang dilakukan oleh Villaver; Andamon dan Tan, yaitu terdapat kontribusi yang relasional antara sikap dan pembelajaran [6]. Naik atau turunnya prestasi dapat bergantung pada sikap yang dimiliki siswa [7]. Hal ini dikarenakan sikap berperan penting dalam mempengaruhi suasana pembelajaran di kelas [9]. Oleh karena itu, diperlukan kesadaran guru untuk memahami sikap yang dimiliki oleh siswanya, baik sikap positif maupun negatif. Karena bukan sesuatu yang tidak mungkin untuk dapat mengubah sikap seseorang. Walaupun perubahannya cukup kompleks dan memerlukan waktu yang relatif lama, serta diperlukan suatu upaya yang dilakukan dengan konsisten sejak dini, agar siswa mampu menumbuhkan sikap positif terhadap geometri [10].

Tabel 4. ANOVA

\begin{tabular}{llcrrrc}
\hline Model & & Sum of Squares & df & Mean Square & F & Sig. \\
\hline 1 & Regression & 426,131 & 1 & 426,131 & 196,068 & 0,000 \\
& Residual & 128,229 & 59 & 2,173 & & \\
& Total & 554,361 & 60 & & & \\
\end{tabular}

a. Predictors: (Constant), attitude

b. Dependent Variable: understanding

\section{SIMPULAN}

Hasil penelitian menunjukkan bahwa sikap geometri berpengaruh signifikan terhadap kemampuan pemahaman konsep matematis siswa, serta menghasilkan model matematis dari regresi linear, yaitu sebagai berikut:

$$
\mathrm{Y}=3,214+0,725 \mathrm{x}
$$

Nilai 3,214 merupakan nilai konstanta yang menunjukkan bahwa jika ada sikap geometri maka pemahaman konsep matematis akan mencapai 35,242. Koefisien regresi $\mathrm{x}$ sebesar 0,725 menyatakan bahwa setiap ada penambahan satu nilai untuk sikap geometri akan meningkatkan kemampuan pemahaman konsep matematis sebesar 0,725 .

Besarnya pengaruh sikap geometri terhadap kemampuan pemahaman matematis adalah sebesar $76,9 \%$, sedangkan $23,1 \%$ dipengaruhi oleh faktor lainnya. Selain itu, sebagian besar siswa merasa bahwa pelajaran geometri menyenangkan dan tidak membosankan, serta dapat diterapkan dalam kehidupan sehari-hari.

\section{DAFTAR PUSTAKA}

[1] M. Ünlü, S. Avcu, and R. Avcu. "The relationship between geometry attitudes and self-efficacy beliefs towards geometry". Procedia - Social Behavioral Sciences, vol. 9, pp. 13251329, 2010.

[2] G. Sunzuma, M. Zezekwa, and N. Masocha. "Secondary school students' attitudes towards their learning of geometry: a survey of bindura urban secondary schools". Greener Journal Educational Research, vol. 3, no. 8, pp. 2276-7789, 2013.

[3] D. Y. Aktaş and M. C. Aktaş. "Investigating high school students' attitudes towards geometry according to different variables: sample of ordu city". Dicle Üniversitesi Ziya Gökalp Eğitim Fakültesi Dergisi, vol. 18, pp. 156-167, 2012.

[4] C. C. Gloria. "Mathematical competence and performance in geometry of high school students". International Journal of Science and 
Technology, vol. 5, no. 2, pp: 53-69, 2015.

[5] M. K. Burns et al. "Using a conceptual understanding and procedural fluency heuristic to target math interventions with students in early elementary". Learning Disabilities Research and Practice, vol. 30, no. 2, pp. 52-60, 2015.

[6] J. C. Andamon and D. A. Tan. "Conceptual understanding, attitude and performance in mathematics of grade 7 students". International Journal Scientific \& Technology Research, vol. 7, no. 8, pp. 96-105, 2018.

[7] J. T. Akaazua, D. C. Bolaji, Y. K. Kajuru, M. Mu, M. Musa, and K. Bala. "Effect of concrete manipulative approach on attitude, retention and performance in geometry among junior secondary school students in
Benue State, Nigeria”. IOSR Journal Research \& Method in Education, vol. 7, no. 6, pp. 80-175, 2017.

[8] A. D. Aksu. "Predicting the geometry knowledge of pre-service elementary teachers". Cumhuriyet International Journal of Education, vol. 2, no. 3, pp. 15-27, 2013.

[9] Y. Dede. "Students' attitudes towards geometry: a cross-sectional study". Jornal Internacional de Estudos em Educação Matemática, vol. 5, no. 1, pp. 85-113, 2012.

[10] A. H. Abdullah, N. H. Ibrahim, J. Surif, and E. Zakaria. "The effects of Van Hiele's phase-based learning on students' geometric achievement and attitude towards geometry". Proceeding - International Conference on Teaching and Learning in Computing and Engineering, pp. 317-324, 2014. 